\title{
Variable diastolic rumbling murmur caused by floating left atrial thrombus
}

\author{
CHIN C CHEN, MING C HSIUNG, BENJAMIN N CHIANG \\ From Department of Medicine, The Veterans General Hospital and Tri-service General Hospital, Taipei, Taiwan, \\ Republic of China
}

SUMMARY A 53 year old man with a history of rheumatic mitral stenosis was admitted to hospital because of recurrent fainting spells. Auscultation showed a variable diastolic rumbling murmur. Simultaneous echo- and phonocardiograms demonstrated a floating left atrial thrombus; when this passed into the left ventricular inflow tract and obstructed the mitral valve orifice the diastolic murmur disappeared.

Since closed commissurotomy continues to be an effective treatment for relieving symptoms in patients with mitral stenosis, ${ }^{2}$ a reliable method is required of detecting left atrial thrombus, which may make this surgical approach hazardous. This paper describes a patient in whom phonocardiography and echocardiography detected the presence of a floating left atrial thrombus.

\section{Case report}

A 53 year old man with a history of rheumatic heart

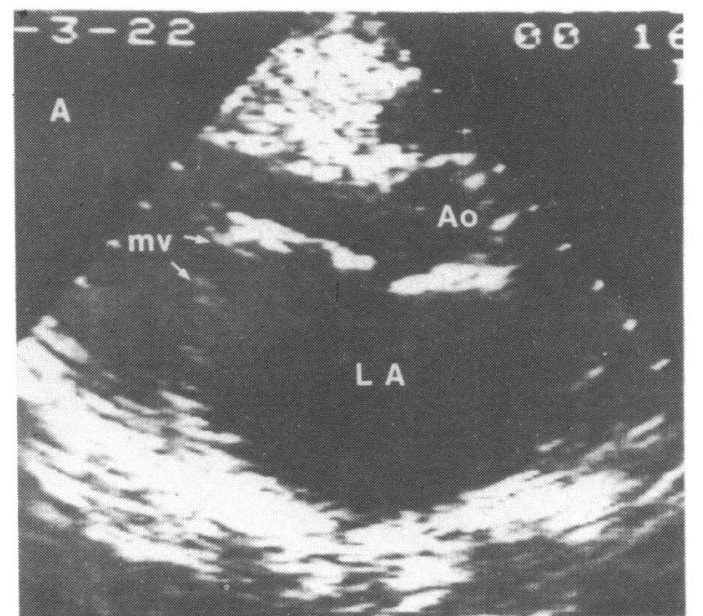

disease who underwent closed mitral commissurotomy 15 years ago was admitted to hospital with recurrent fainting spells. On physical examination the blood pressure was $120 / 80 \mathrm{mmHg}$ and the heart rate was regular at $76 / \mathrm{min}$. The first heart sound was accentuated and a grade $3 / 6$ pansystolic murmur was heard at the cardiac apex radiating to the left axilla. A grade 3/6 apical mid-diastolic murmur was heard in differing parts of diastole and frequently became inaudible. The intensity of the diastolic murmur did not vary with respiration or posture. Neurological examination was normal.

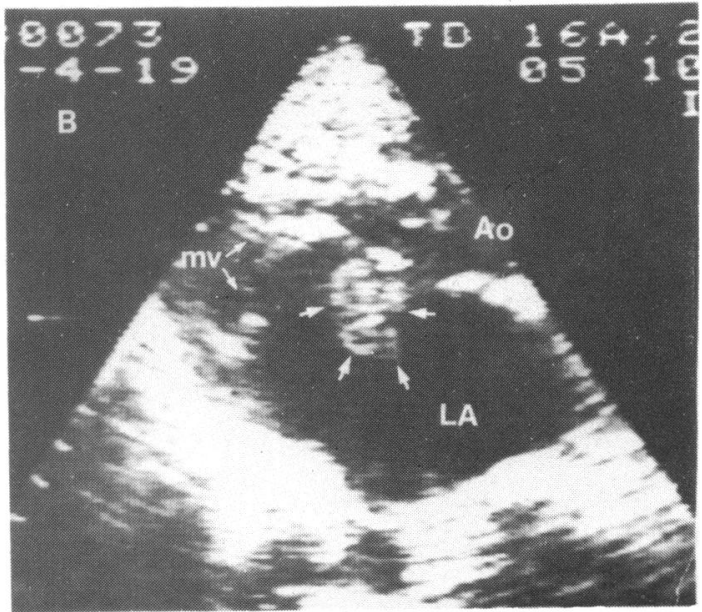

Fig. 1 Parastemal long axis cross-section of the heart. Panel A. A large left atrium (LA) and mural suenosus are seen. Panel B. Large circulating mass within the left atrium (arrows). mv, mitral valve; Ao, aorta. 


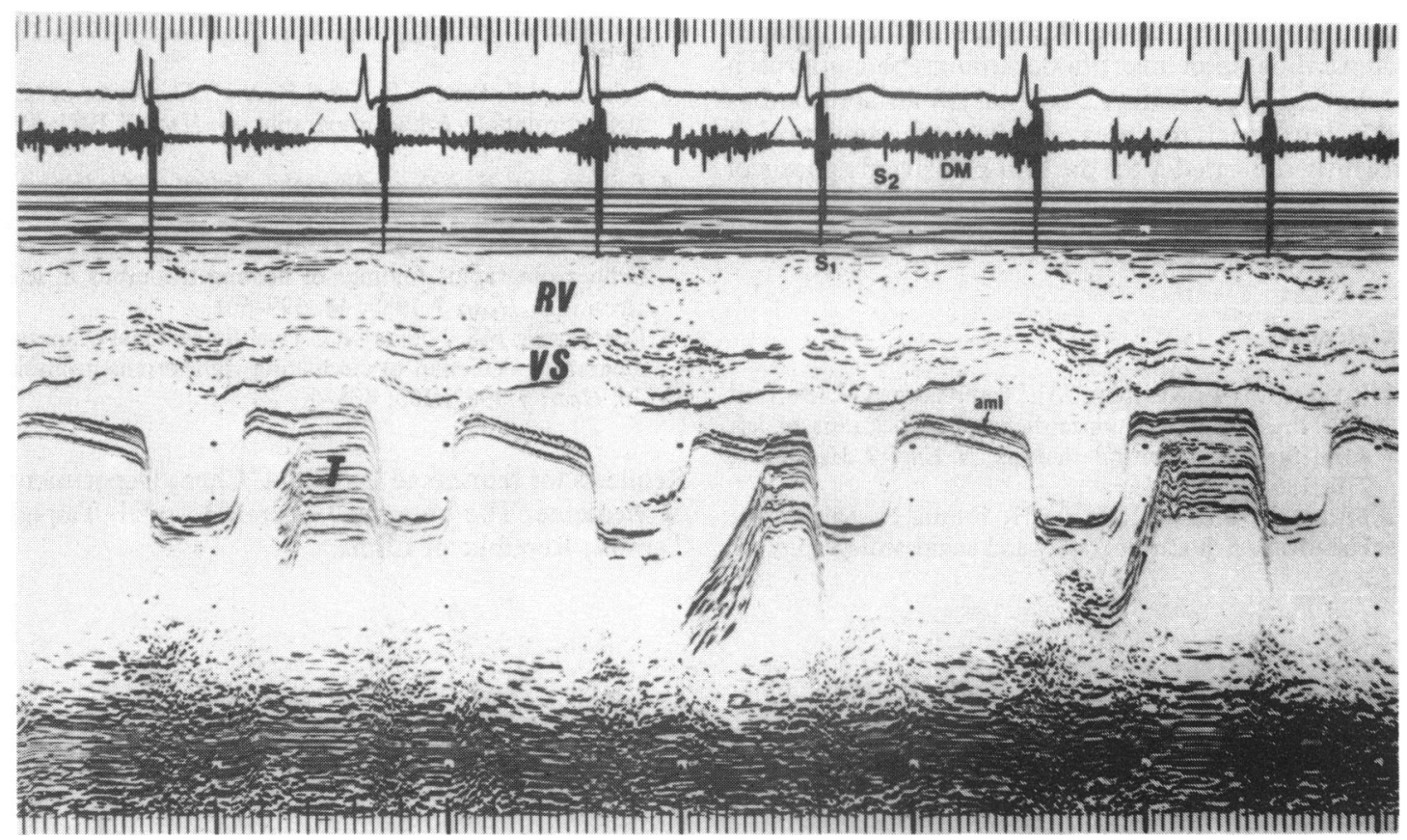

Fig. 2 Simultaneous phonocardiographic and echocardiographic recording showed frequent disappearance of the diastolic murmur as the floating mass $(T)$ moved into the left ventricular inflow tract. DM, diastolic murmour; $R V$, right ventricle; VS, ventricular septum; aml, anterior mitral leaflet.

M-mode and two dimensional echocardiography were performed using an Irex phased array system. Fig. 1A is a parasternal left ventricular long axis view obtained four weeks before admission. It showed an enlarged left atrium with mitral stenosis. No intracavitary masses were noted. Two dimensional echocardiography was repeated on admission and again showed an enlarged left atrium and mitral stenosis. A new large mass of echoes within the left atrial cavity was observed, however (Fig. 1B), which was circulating freely and erratically. M-mode echocardiogram disclosed a moving broad band of echoes within the left atrial cavity as well as a mass of echoes detected randomly posterior to the anterior mitral leaflet during diastole. Simultaneous phonocardiographic and echocardiographic recordings showed irregular timing of the diastolic murmur corresponding to the circulating echo mass obstructing the mitral valve orifice (Fig. 2). Cardiac catheterisation showed modest mitral regurgitation and the presence of a large rounded mass in the left atrium. The pulmonary wedge pressure and left ventricular pressure were $40 \mathrm{mmHg}$ (mean) and $120 / 20 \mathrm{mmHg}$, respectively. Subsequently, the patient underwent open mitral commissurotomy and a large left atrial thrombus measuring $1.9 \times 1.7 \mathrm{~cm}$ was found to lie freely within the left atrium. The left atrial appendage was also filled with organised thrombus.

\section{Discussion}

A floating left atrial thrombus is uncommon. Because of its potential in causing fatal systemic emboli or mitral valve orifice occlusion, early diagnosis is extremely important. Both M-mode and two dimensional echocardiograms constitute an imperfect method for the detection of immobile left atrial thrombus. ${ }^{3}$ The usefulness of echocardiography in demonstrating mobile left atrial masses such as left atrial myxoma, however, has been well established. There are two previous case reports ${ }^{4}$ of floating left atrial thrombi detected by echocardiography. The characteristic M-mode echocardiographic finding was the appearance of mass echoes posterior to the anterior mitral leaflet without synchronisation with the cardiac cycle. Furukawa et al. ${ }^{5}$ have also described the two dimensional echocardiographic appearance of floating left atrial thrombus as variable in size and position in each cardiac cycle. Rosenzweig and Nanda $^{6}$ reported the case of a patient with a floating right atrial thrombus detected by two dimensional echocardiography. In previous reports, however, clinical auscultation and phonocardiography did not show the intermittent irregular disappearance of the diastolic murmur, as in our case in which disappearance of the diastolic murmur occurred when the floating left atrial thrombus obstructed the mitral orifice. 
We therefore emphasise the value of the combined echocardiographic and phonocardiographic approach in the diagnosis of either a floating left atrial thrombus or a left atrial myxoma. While anticoagulation is urgently indicated after the non-invasive diagnosis of left atrial thrombus, a floating left atrial thrombus should be removed immediately by surgery.

\section{References}

1 Parker BM, Friedenberg MJ, Templeton AW, Burford TH. Pre-operative angiocardiographic diagnosis of left atrial thrombi in mitral stenosis. $N$ Engl f Med 1965; 273: $136-40$.

2 Furuse A, Mizuno I, Inoue H, Furuta N, Saigusa M, Harady Y. Echocardiography and angiocardiography for detection of left atrial thrombus. $\mathcal{f p}_{\mathrm{p}}$ Heart $\mathcal{f}$ 1976; 17: 163-71.

3 Schweizer P, Bardos P, Erbel R, et al. Detection of left atrial thrombi by echocardiography. $\mathrm{Br}$ Heart $\mathcal{F} 1981$; 45: 148-56.

4 Feigenbaum H. Echocardiography. 3rd ed. Philadelphia: Lea \& Febiger, 1981: 520.

5 Furukawa K, Katsume H, Matsukubo H, Inoue D. Echocardiographic findings of floating thrombus in left atrium. Br Heart f 1980; 44: 599-601.

6 Rosenzweig MS, Nanda NC. Two dimensional echocardiographic detection of circulating right atrial thrombi. Am Heart f 1982; 103: 435-6.

Requests for reprints to Dr Chin C Chen, Department of Medicine, The Veterans General Hospital, Taipei, Taiwan, Republic of China. 